\title{
Apparent Total Body Clearance Rate
}

National Cancer Institute

\section{Source}

National Cancer Institute. Apparent Total Body Clearance Rate. NCI Thesaurus. Code C154701.

The apparent total body clearance for intravascular administration. 